\title{
EVALUATING GREEN IT IN LOCAL ADMINISTRATION
}

\author{
Manuel Landum ${ }^{1}$ \\ M. M. M. Moura ${ }^{2}$ \\ Leonilde Reis ${ }^{3}$
}

DOI: https://doi.org/10.31410/ITEMA.2020.1

\begin{abstract}
This work is prompted by the massive use of Information and Communication Technologies, the need for alignment with the business, the concern for integrated management and the need to protect natural resources and the environment. This article aims to present a framework, multidimensional and multidisciplinary, from the perspective of sustainability, in the treatment of Green IT, involving environmental issues and social responsibility, Governance of Information Technologies and Financial Management, in the context of Public Administration, more specifically in local administration. The methodology used is based on the literature review, in the field of thematic, and on a case study in development in local government, in order to analyze the feasibility and suitability with the validation of the framework. The main results obtained in the case study focus on the use of technology allied to Green IT, with theoretical reflexes for environmental quality and with possible cost reduction.
\end{abstract}

Keywords: Green IT, Information and communication technologies, Sustainability.

\section{INTRODUCTION}

$\mathrm{P}$ ublic administration, and particularly local administration (LA), is encumbered with a set of rules that make it particularly difficult to implement changes. On the other hand, the use of information and communication technologies (ICT) to support current activities is provoking a high rate of change in the business processes of an organization. Aligned with this, one should note that ecological considerations are a matter of social responsibility that has been gaining visibility in recent years. Green information technology (Green IT) is naturally associated with these themes (Chugh, Wibowo, \& Grandhi, 2016), and can be the vehicle for achieving environmental sustainability.

Our concern is the governance of ICT in a local public administration scenario. In fact, there is a social responsibility that cannot be forsaken in the decisions and actions taken by enterprises and it is more so when local public administration is concerned. Having drawn a proposal of good practices that assure the governance of ICT while maintaining the alignment with green IT (Landum, Moura, \& Reis, 2020), we then sought to reconcile the green information technology and green information systems perspectives. Having reviewed the state of the art of management practices (Landum, Reis, \& Moura, 2020) in what concerns the optimization the governance of ICT a need was felt for a general model to evaluate alternative measures and quantify their suitability.

Universidade do Algarve, Portugal, DEEI/FCT, Campus de Gambelas, Faro, 8005-139 Faro, Portugal Universidade do Algarve, Portugal, DEEI/FCT, Campus de Gambelas, Faro, 8005-139 Faro, Portugal Polytechnic Institute of Setúbal, Portugal, Campus do IPS, Estefanilha, Setúbal, Portugal 
In the perspective of the author (Landum, 2018), the implementation and optimization of ICT management practices, in Local Administration (LA), should consider the reduction/optimization of costs, ubiquity, in the search for greater productivity, guaranteeing safety standards.

Considering a change, or a new process to be implemented, one can separately evaluate how that change will impact an ecological dimension. The literature is mostly unanimous considering that the ecological impact can be equated in terms of carbon footprint, reduction of the number of products for recycling and sustainable use of resources including energy. The evaluation on a social dimension translates to how a service is perceived by its end users. In our present case, one must consider the employees of the ICT department but also the citizens of the municipality. In what concerns the financial impact of a measure again it is twofold as one can distinguish direct and indirect costs and how they translate to the global welfare of the community. A preliminary model for a quantitative evaluation of the alignment with Green IT of a process or operating change is presented. Following this introduction, in the second section the impact of Green IT on LA is described, and in the third section, some final remarks and perspectives of future work are presented.

\section{IMPACT OF GREEN IT ON LOCAL GOVERNMENT}

The section presents the theme of Green IT, and the way it has gained status taking into account the global movement that has developed, emerging with its environmental concerns, the problem of climate change, sustainability and the promotion of social and environmental responsibility, linked to technology. Currently the "Green technology plays a fundamental role in achieving the global sustainable development goals. However, the lack of a widely accepted classification system for green technology often hinders the development and adoption of green technology" (Guo, et al., 2020). The European Union (EU), in December 2019, launched the European Ecological Agreement, which states that "Climate change and environmental degradation are an existential threat to Europe and the world. To overcome these challenges, Europe needs a new growth strategy that transforms the Union into a modern, resource-efficient and competitive economy where there are no net emissions of greenhouse gases by 2050; economic growth is decoupled from resource use and no person and no place are left behind. The European Green Deal is our roadmap for making the EU's economy sustainable. This will happen by turning climate and environmental challenges into opportunities across all policy areas and making the transition just and inclusive for all" (Commission, 2019).

The EU has defined as a strategy the launch of the green agreement and the aim is that by 2050 there will be no greenhouse gas emissions, currently "it is by no means certain our society has the capacity to endure - at least in such a way that the nine billion people expected on Earth by 2050 will all be able to achieve a basic quality of life. The planet's ecosystems are deteriorating, and the climate is changing. We are consuming so much, and so quickly, that we are already living far beyond the earth's capacity to support us" (ERM Group Company, 2020). The author (Sulaiman, Naqshbandi, \& Dezdar, 2015) mentions that "This is a big challenge, and not just for business and economics. It is a call for massive social, political, technological, cultural and behavioral transition. We will need governments to set incentives, targets and rules for a level playing field, civil society actors to hold us to account and to experiment with new ways of delivering social impact".

In the face of this challenge, it is necessary and evident that (Cai, Chen, \& Bose, 2013) the adoption of practices and tools that allow the general management, being an increasing 
occurrence in local public organizations. These organizations are shifting the paradigm from management to sustainability, and LA is developing its projects faster than other levels of the public sector, notably PA, regarding integrating environmental and sustainability aspects into operations and strategies. One of the ways to promote the implementation of such practices is "aware-ness of sustainable ICT practices can help organizations to adopt various strategies in developing effective sustainability work practices and educating their employees" (Chugh, Wibowo, \& Grandhi, 2016). Aware of the situation, the municipality understudy, strategically embarked on the renovation of its aged computer park, adopting disruptive technologies, environmentally friendly and simultaneously self-sustaining. It should be highlighted that one of the objectives of environmental sustainability is to solve the current needs, without compromising the needs of future generations and this will only be possible if existing natural resources are not currently exhausted.

For the authors (Chugh, Wibowo, \& Grandhi, 2016) environmental sustainability can be achieved through the adoption of correct practices in the design, manufacture, use and disposal of ICT. Green ICT, influenced by user practices or the use of appropriate technology to make the environment sustainable, should help reduce the environmental footprint of agencies, so (Moreno \& Reis, 2012) they consider that the use of Information Systems (IS) as a means of supporting and improving the organization's activities is indisputable. IS are a key contribution to efficient resource management to achieve an organization's objectives. It should be highlighted that the future of ICT will increasingly be based on the vector of sustainability, therefore (Meneses, 2019) the numerous emerging technologies that characterize industry 4.0, namely artificial intelligence, internet of things (IoT), nano-technology, quantum computing, drones, 3D printing, blockchain, among others, will have uses increasingly focused on sustainability (i.e. on people, the environment and governance processes).

The Green IT approach is often combined with sustainability, knowing that the "Sustainable development is a widely debated issue around the world and there has been increasing pressure on firms to adopt practices that are more environmentally friendly. Among the most crucial practices are Green Information Technology (IT) practices, as most firms use some form of IT to perform their daily transactions" (Sulaiman, Naqshbandi, \& Dezdar, 2015), i.e. supports your systems in IT solutions. The concept of Green IT is not equal to IT for Green, but it complements the two definitions "Green IT is the practice of designing, manufacturing, using and disposing of computer, servers and associated subsystems efficiently and effectively with minimal or no impact on the environment, with a strong focus on improving energy efficiency and equipment utilization through steps such as designing energy efficient chips, virtualization, reducing data center energy consumption, using renewable energy to power data centers, and reducing electronic waste" (Cai, Chen, \& Bose, 2013), in the perspective of its authors. The concept of IT for Green is based on the "use of information systems to enhance sustainability across the economy, with a focus on IT as a solution" (Cai, Chen, \& Bose, 2013).

In short, "local governments are faced with the need to be part of the change from the perspective of sustainability and integrate good practices to improve their own performance" (Cai, Chen, \& Bose, 2013).

\section{EVALUATING GREEN IT}

Organizations, more specifically LA, feel the need to find models of good ICT practices, which can simultaneously be sustainable, contribution to environmental improvement and align with Green IT, so a schematic plan of a developed Framework is presented, where in this article 
only a few vectors will be addressed. We consider that evaluating the alignment with Green IT should include business objectives as well as productivity, reliability, service availability, optimization of management times, information security, cost reduction, environmental impact, and customer satisfaction.

Thus, we equate the alignment with Green IT (1)

$$
\text { GreenIT Alignment }=0.3 \mathrm{IT}+0.2 \mathrm{Fin}+0.3 \mathrm{Env}+0.2 \mathrm{Soc}
$$

considering the contribution of four dimensions, namely IT, financial (Fin), environmental (Env) and social (Soc).

It is thus necessary to distribute the contributing valences by the corresponding dimensions and to translate each of the valences to indicators. In each dimension, the relevant indicators are evaluated. The positive (+) or negative (-) value of the indicator will convey if it furthers or hinders the green alignment, respectively, and is presented in the direction column. The relative relevance of an indicator is conveyed by a weight (in \%).

IT valences: Hardware, software, information systems, security, governance.

Financial valences: Direct and/or indirect costs of IT.

Environmental valences: Environmental impact including $\mathrm{CO}_{2}$ emissions, use of natural resources, contribution to global warming, recycling.

Social valences: satisfaction of the citizen, speed of response, number of trips, time on the move, image of the municipality.

The IT dimension (IT) aggregates the indicators that convey the operational goals, namely, to optimize reliability, service availability, optimization of management times, information security and productivity (Table 1). The financial dimension (Fin) aggregates the indicators that relate to cost, either capital expenditure (CapEx) or operating expenditure (OPEX) (Table 2). The indicators included in the environmental dimension are presented in Table 3. The indicators considered in the social dimension convey social satisfaction with the services provided and the perceived image of the municipality (Table 4).

Table 1. IT indicators

\begin{tabular}{|l|c|r|}
\hline Indicators & Direction & Weight factor \\
\hline reliability & + & $10 \%$ \\
\hline management times & - & $5 \%$ \\
\hline service availability & + & $10 \%$ \\
\hline productivity & + & $15 \%$ \\
\hline quality management & + & $5 \%$ \\
\hline number of malfunctions & - & $10 \%$ \\
\hline information security & + & $20 \%$ \\
\hline ubiquity of access & + & $10 \%$ \\
\hline reduction of file space on digital support & + & $5 \%$ \\
\hline number of printing equipment's & - & $5 \%$ \\
\hline stock of consumables & - & $5 \%$ \\
\hline
\end{tabular}


Table 2. Financial indicators

\begin{tabular}{|l|c|r|}
\hline Indicators & Direction & Weight factor \\
\hline cost of infrastructure & - & $25 \%$ \\
\hline equipment lifetime & + & $20 \%$ \\
\hline training & + & $10 \%$ \\
\hline energy costs & - & $20 \%$ \\
\hline number of printing equipment's & - & $15 \%$ \\
\hline consumable costs & - & $10 \%$ \\
\hline
\end{tabular}

Table 3. Environmental indicators

\begin{tabular}{|l|c|r|}
\hline Indicators & Direction & Weight factor \\
\hline energy consumption & - & $20 \%$ \\
\hline $\mathrm{CO}_{2}$ emissions & - & $20 \%$ \\
\hline preservation of natural resources & + & $10 \%$ \\
\hline suitability for recycling & + & $5 \%$ \\
\hline global warming & - & $5 \%$ \\
\hline paper file space & - & $10 \%$ \\
\hline paper use & - & $5 \%$ \\
\hline deforestation & - & $15 \%$ \\
\hline number of printing equipment & - & $5 \%$ \\
\hline stock of consumables & - & $5 \%$ \\
\hline
\end{tabular}

Table 4. Social indicators

\begin{tabular}{|l|c|r|}
\hline Indicators & Direction & Weight factor \\
\hline satisfaction of the citizen & + & $10 \%$ \\
\hline image of the municipality & + & $10 \%$ \\
\hline well-being of employees & - & $10 \%$ \\
\hline time in the circulation of information & - & $15 \%$ \\
\hline speed in the response to the citizen & + & $10 \%$ \\
\hline number of trips to the service & - & $10 \%$ \\
\hline loss of time on travel & - & $10 \%$ \\
\hline travel costs to citizens & - & $15 \%$ \\
\hline service times & - & $10 \%$ \\
\hline
\end{tabular}

Finally, the evaluation of a new process or the global activity will be qualitatively resumed as presented in

Table 5.

Table 5. Green IT Alignment

\begin{tabular}{|l|l|}
\hline Nominal score & Qualitative score \\
\hline$<=20 \%$ & Very little aligned \\
\hline$>20 \% \wedge<=45 \%$ & Little lined up \\
\hline$>45 \% \wedge \wedge=75 \%$ & Aligned \\
\hline$>75 \% \wedge \wedge=90 \%$ & Very aligned \\
\hline$>90 \% \wedge 100 \%$ & Strongly aligned \\
\hline
\end{tabular}


This model can be used to support strategic decisions and informed choice on changes such as substituting CRT monitors with LCDs, substituting desktop computers by thin clients or making services available online can be facilitated.

\section{CONCLUSION}

The main conclusions focus on the presentation of indicators underlying the various dimensions towards the optimization of ICT management practices in LA to contribute to Green IT. The multidimensional and multidisciplinary Framework has implicitly the possibility of assigning weights allowing for the specificity of each LA thus contributing, in a sense of flexibility and suitability, to promote sustainability and contribute to Green IT.

About the impact of Green IT on LA, the paper presents several contributes in this area, particularly with regard to the quantification of the measures adopted, considering that the approximations to Green IT can be evaluated by the dimensions IT, Financial, Environmental and Social. It is also considered that it is added value that the dimensions under study are comprehensive to include several valences.

As perspectives of future work, it is intended to reflect on the scope of the dimensions under study as well as to analyze the indicators and relative relevance thus contributing to the creation of a quantitative model, applicable by PA and LA, to support the decision-making process while aligning with Green IT.

\section{REFERENCES}

Cai, S., Chen, X., \& Bose, I. (2013). Exploring the role of IT for environmental sustainability in China: An empirical analysis. Retrieved: 28th September 2020, https://www.sciencedirect.com/science/article/pii/S0925527313000480?via\%3Dihub

Chugh, R., Wibowo, S., \& Grandhi, S. (2016). Environmentally sustainable Information and Communication Technology usage: awareness and practices of Indian Information and Communication Technology professionals. Retrieved: 29th September 2020, https://www.sciencedirect.com/science/article/pii/S0959652616304590

Commission, E. (2019). A European Green Deal - Striving to be the first climate-neutral continent. Retrieved: 15th September 2020, https://ec.europa.eu/info/strategy/priorities2019-2024/european-green-deal_en

ERM Group Company. (2020). Sustainability: Can our society endure? Retrieved: 26th September 2020, https://sustainability.com/sustainability/

Guo, R., Lv, S., Liao, T., Xi, F., Zhang, J., Zuo, X., Zhang, Y. (2020). Classifying green technologies for sustainable innovation and investment. Retrieved: 17th September 2020, https://www.sciencedirect.com/science/article/pii/S0921344919304860

Landum, M. (2018). Conceção de abordagem para otimização das práticas de gestão das TIC. Retrieved: $\quad$ 17th September 2020, https://repositorio.ipsantarem.pt/bitstream/10400.15/2634/1/eBook_CAPSI\%202018_R icardoSaoJoao.pdf

Landum, M., Moura, M. M., \& Reis, L. (2020). Boas Práticas de TIC em alinhamento com o Green IT. Retrieved: 22nd September 2020, CISTI'2020 - 15th Iberian Conference on Information Systems and Technologies: http://www.aistic.org/cisti2020/oc20/modules/request.php?module=oc_program\&action $=$ summary.php\&id $=154$ 
Landum, M., Reis, L., \& Moura, M. M. (2020). Concept of approach to optimize ICT management practices: State of the art. Em L. C. Carvalho, L. Reis, A. Prata, \& R. Pereira, Handbook of Research on Multidisciplinary Approach to Entrepreneurship, Innovation, and ICTs (pp. pp. 174-199). IGI Global. doi:10.4018/978-1-7998-4099-2.ch009

Meneses, J. W. (2019). A sustentabilidade em 2019. Retrieved: 26th September 2020, https://www.bcsdportugal.org/noticias/a-sustentabilidade-em-2019

Moreno, J., \& Reis, L. (2012). Proposta de implementação de um portal corporativo - Caso Ana Aeroportos de Portugal, S.A. Retrieved: 25th September 2020, https://comum.rcaap.pt/bitstream/10400.26/30018/1/Proposta_Implementa\%c3\%a7\%c3 \%a3o_Portal_Corporativo_Ana_Aeroportos_XXII_Jornadas_Luso_Espanholas.pdf

Sulaiman, A., Naqshbandi, M. M., \& Dezdar, S. (2015). Impact of adoption of Green IT practices on organizational performance. Retrieved: 26th September 2020, https://www.researchgate.net/publication/280949290_Impact_of_adoption_of_Green_I T_practices_on_organizational_performance 